\title{
Spontaneous Intramural Duodenal Hematoma: A Rare Complication of Pancreatitis
}

\author{
Ravi Kumar ${ }^{1}$, Pal Satyajit Singh Athwal ${ }^{2}$, Mukesh Kumar $^{3}$, Kanchan Devi $^{1}$, Sukhmanii Kahlon ${ }^{4}$ \\ 1. Internal Medicine, Jinnah Sindh Medical University, Karachi, PAK 2. Internal Medicine, Saraswathi Institute of \\ Medical Sciences, Hapur, IND 3. Neurology, Shaheed Mohtarma Benazir Bhutto Medical University, Larkana, PAK 4. \\ Internal Medicine, Medical University of the Americas, Camps, KNA
}

Corresponding author: Pal Satyajit Singh Athwal, satyajitsinghathwal@gmail.com

\begin{abstract}
Intramural duodenal hematoma is an uncommon entity, usually associated with trauma. Spontaneous intramural duodenal hematoma is an even more rare phenomenon reported in patients with anticoagulation therapy, gastrointestinal endoscopy procedure or coagulopathy. We report a case of spontaneous intramural duodenal hematoma in a 30-year-old male as a pancreatitis complication, very few cases have been known in the past and still a lot is to be discovered about this rare hematoma associated with pancreatitis. This condition can have catastrophic consequences and should be managed appropriately.
\end{abstract}

Categories: Internal Medicine, Gastroenterology

Keywords: intramural duodenal hematoma, pancreatic origin, pancreatitis

\section{Introduction}

In 1838, during an autopsy, McLauchlan first introduced intramural duodenal hematoma [1]. Hematoma is formed inside the wall of duodenum and is usually seen in trauma patients. Intramural duodenal hematoma can lead to gastrointestinal obstruction, perforation, intussusception which can be life threatening.

Spontaneous intramural duodenal hematoma cases are very scarcely reported in the past which were linked to coagulation disorders, anticoagulation therapy and endoscopy procedures $[2,3]$. Spontaneous intramural duodenal hematoma secondary to pancreatic pathology is associated with pancreatic carcinoma, chronic pancreatitis and ectopic pancreas [4]. Pathophysiology and prognosis of spontaneous intramural hematoma of pancreatic origin remain unknown. We report a case of spontaneous intramural duodenal hematoma in 30-year-old male patient with history of pancreatitis three days ago.

Received 05/21/2020 Review began 06/01/2020 Review ended 06/01/2020 Published 06/07/2020

(c) Copyright 2020

Kumar et al. This is an open access article distributed under the terms of the Creative Commons Attribution License CC-BY 4.0., which permits unrestricted use, distribution, and reproduction in any medium, provided the original author and source are credited.

\section{Case Presentation}

A 30-year-old-male with history of alcohol abuse presented with a complaint of severe epigastric pain. The pain was diffuse across his abdomen, 10/10 in intensity and sharp in quality. The patient was diagnosed with acute pancreatitis and was discharged three days ago. On physical examination, everything was normal except diffuse abdominal tenderness. A nasogastric tube was inserted with improvement in his pain along with fluid management. Analgesics in the form of morphine was used to control the pain. Lab investigation as in Table 1 revealed a drop in hemoglobin $(\mathrm{Hb})$ from $14 \mathrm{gm} / \mathrm{dl}$ to $9 \mathrm{gm} / \mathrm{dl}$, mild thrombocytopenia, hypomagnesemia, hypophosphatemia, hyponatremia, hypokalemia and hypocalcemia. Coagulation studies and lactic acid were within normal range. 


\section{Cureus}

\begin{tabular}{ll}
\hline Lab values & \\
\hline Hemoglobin & $9 \mathrm{gm} / \mathrm{dl}$ \\
WBC & $11890 / \mathrm{mm}^{3}$ \\
Calcium & $8.3 \mathrm{mg} / \mathrm{dl}$ \\
PT & $12 \mathrm{sec}$ \\
ALT & 50 \\
AST & 110 \\
INR & 0.95 \\
\hline
\end{tabular}

\section{TABLE 1: Lab values}

WBC: White blood cell; PT: Prothrombin time; ALT: Alanine transaminase; AST: Aspartate transaminase; INR: International normalized ratio.

Chest X-ray and ECG were ordered with assumption of transferring patient for surgery because of presentation with acute abdomen. The patient was evaluated for pancreatitis complications with ultrasonography which showed gallbladder with microlithiasis, sludge and diffuse echogenicity of liver. CT scan showed a 13-cm duodenal hematoma as shown in Figure 1, mild ascites and reactive colitis.

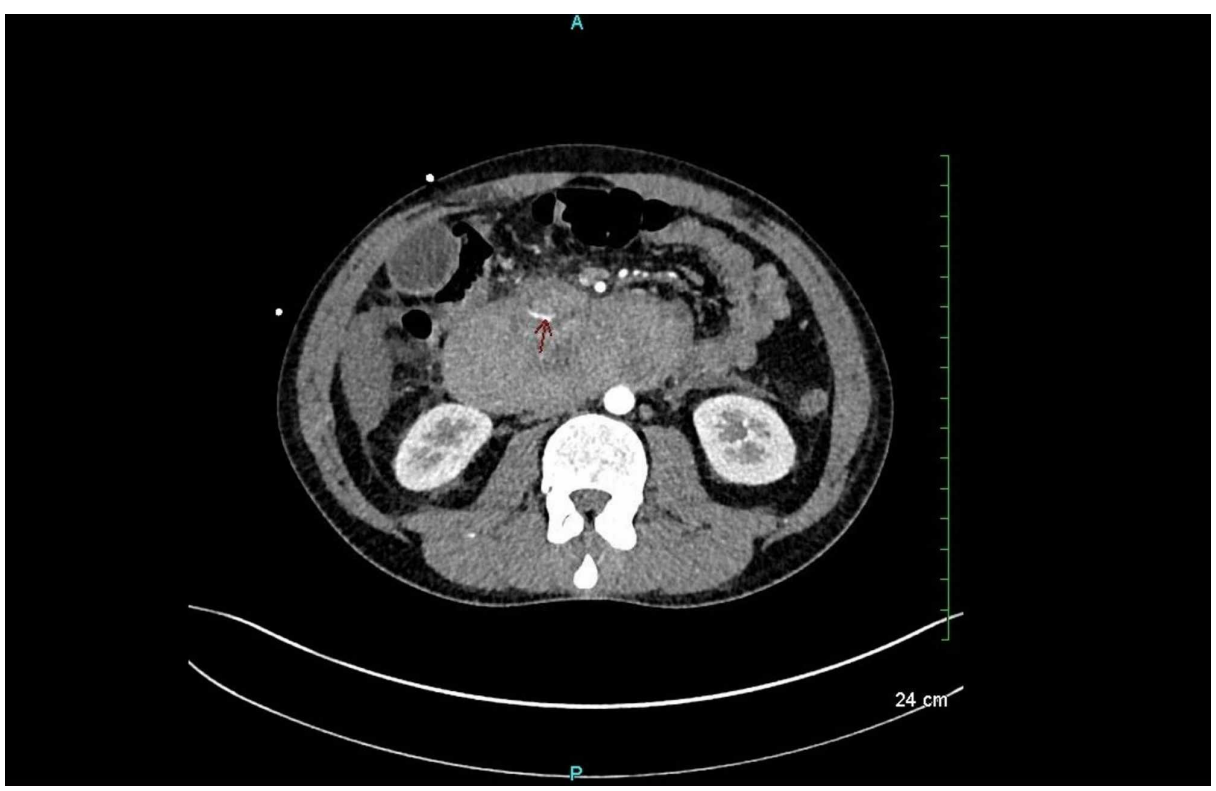

FIGURE 1: CT scan demonstrating intramural duodenal hematoma.

The surgery team was consulted but they refused any intervention due to low hemoglobin and fear of further worsening of hematoma. The patient was managed conservatively with total parenteral nutrition, nasogastric suction, electrolyte correction and pain control. Repeat CT scan a few days later showed regression of hematoma. After 14 days of hospitalization, the patient became asymptomatic and was discharged.

\section{Discussion}

The first case of intramural duodenal hematoma of pancreatic origin was reported in 1938 by Oppenheimer; very few cases have been reported in the past [5]. Pancreatic causes include acute pancreatitis, chronic pancreatitis, ectopic pancreas and pancreatic tumor [6]. This case presented with acute severe abdominal pain while cases in the past had varied presentation with symptoms of gastric outlet obstruction, acute abdominal pain, vomiting and jaundice due to biliary outflow obstruction [7-9]. The hematoma is usually confined inside subserosal layer of duodenum. Pathophysiology remains uncertain although believed to be vascular erosion due to release of proteolytic enzymes from inflamed pancreas. Another hypothesis explains 
hematoma due to vascular erosion due to ectopic pancreas in the wall of duodenum [9]. CT and MRI remain the most sensitive diagnostic modalities for intramural duodenal hematoma - both are very useful for diagnosis as well as follow-up. Follow-up imaging should be done within two weeks [6]. Management includes conservative measures like fluid resuscitation, pain control and imaging follow-up as performed in this case, because the patient was high risk for the surgery. Arterial embolization is an effective management modality for stable patients [10]. Surgical intervention like laparotomy is reserved for unstable patients. It is a rare complication of pancreatitis which requires further research to establish pathophysiology and prognosis in such cases.

\section{Conclusions}

Intramural duodenal hematoma is a rare condition in itself which is traumatic in origin. Spontaneous intramural duodenal hematoma as a complication of pancreatitis is an even more rare occurrence, and only few cases were found to be reported in the database. Familiarity of this condition is important to establish timely diagnosis and ruling out other complications of pancreatitis.

\section{Additional Information \\ Disclosures}

Human subjects: Consent was obtained by all participants in this study. Conflicts of interest: In compliance with the ICMJE uniform disclosure form, all authors declare the following: Payment/services info: All authors have declared that no financial support was received from any organization for the submitted work. Financial relationships: All authors have declared that they have no financial relationships at present or within the previous three years with any organizations that might have an interest in the submitted work. Other relationships: All authors have declared that there are no other relationships or activities that could appear to have influenced the submitted work.

\section{References}

1. McLauchlan J: Fatal false aneurysmal tumor occupying nearly the whole of the duodenum . Lancet. 1838, 2:203-205.

2. Bodnár Z, Várvölgyi C, Tóth J, Sápy P, Kakuk G: Intramural duodenal hematoma complicating acute necrotizing pancreatitis. Gastrointest Endosc. 2000, 52:791-793. 10.1067/mge.2000.109587

3. Leundji H, Cuingnet P, Simon M, Boruchowicz A: Duodenal hematoma associated with thrombopenia in chronic alcoholic pancreatitis. (Article in French). Gastroenterol Clin Biol. 2002, 26:185-186.

4. Dubois J, Guy F, Porcheron J: A pancreatic-induced intramural duodenal hematoma: a case report and literature review. Hepato-gastroenterology. 2003, 50:1689-1692.

5. Oppenheimer GD: Acute obstruction of the duodenum due to submucosal hematoma . Ann Surg. 1933, 98:192-196. 10.1097/00000658-193308000-00005

6. Ma JK, Ng KK, Poon RT, Fan ST: Pancreatic-induced intramural duodenal haematoma. Asian J Surg. 2008, 31:83-86. 10.1016/S1015-9584(08)60063-9

7. Fesenmyer ME, Nelson DB: Intramural duodenal hematoma due to pancreatitis. J Clin Gastroenterol. 1998, 26:350-352. 10.1097/00004836-199806000-00033

8. Giraud RM, Berzin S, Shein DM: Acute relapsing pancreatitis complicated by ruptured intramural duodenal haematoma. J R Coll Surg Edinb. 1986, 31:247-249.

9. van Spreeuwel JP, van Gorp LH, Bast TJ, Nadorp JH: Intramural hematoma of the duodenum in a patient with chronic pancreatitis. Endoscopy. 1981, 13:246-248. 10.1055/s-2007-1021697

10. Fitzpatrick J, Bhat R, Young JA: Angiographic embolization is an effective treatment of severe hemorrhage in pancreatitis. Pancreas. 2014, 43:436-439. 10.1097/mpa.0000000000000051 